\title{
INSPIRASI KISAH DALAM MENSTIMULASI CHARACTER BUILDING ANAK USIA DINI
}

\author{
Mariana \\ Institut Agama Islam Sunan Giri Ponorogo \\ Email: mar14na1212@gmail.com
}

\begin{abstract}
The greatest trust of parents and educators is to build character and quip a child with knowledge. Television shows are examples of audio-visual media that affect children's characteristics. Early childhood is a vulnerable age in all directions of learning. Character planting will be formed easily without thinking deeply about themselves. The choice of their chois can make them behave, speak, speak or can be interpreted as the character that grows will resemble what they often hear and see. This research uses qualitative case study approaches. The technique used and data retrieval uses observation, interviews, documentation and data analysis. The object used as the informant in this study was determined purposively, the reasis more, namely eight early childhood on the road Dewi Khunthi Pulosari Jambon Ponorogo. The results of the study show that there are character education values in the cartoon upin and ipin. There is huge enthusiasm of early childhood in the way of Dewi khunthi. That even character figures in animated film Upin and Ipin provide a stimulus in planting the character of early childhood in accordanece with early childhood development, enter and provide effective example in fosting early childhood character.
\end{abstract}

Key words; stimulation, character education, animated film.

\section{PENDAHULUAN}

Amanah terbesar orang tua dan pendidik adalah membangun karakter dan membekali seorang anak dengan ilmu. Menurut Zaim Elmubarok (2008:102) membangun karakter (character building) adalah proses mengukir atau memahat jiwa sedemikian rupa sehingga berbentuk unik, menarik, dan dapat dibedakan dengan orang lain. Pemilihan tanyangan dan pendampingan orang tua menjadi bekal anak mengenal dunia. Tayangan televisi merupakan salah satu contoh media audio visual yang dapat memengaruhi karakteristik anak dalam sisi berlogat, bersosial, dan bertingkah laku sesuai dengan karakter yang mereka tonton. Maraknya tayangan televisi dan suguhan acara-acara yang menarik membuat audien betah menghabiskan waktunya dengan hal tersebut. Salah satu tayangan yang tidak membatasi usia pemirsanya adalah film animasi.

Film animasi merupakan film pilihan anak usia dini yang memiliki durasi lama. Salah satu film tersebut adalah film animasi Upin dan Ipin. Film ini ditayangkan dengan durasi yang lama dengan judul yang diulang-ulang. Anak usia dini adalah anak yang memiliki usia rentan dalam segala arah pembelajaran. Penanaman karakter akan terbentuk dengan mudah di usia tersebut. Film animasi "Upin dan Ipin" dan "Meracuni Dunia Anak" merupakan dua film yang dapat membawa anak untuk menirukan karakter tokoh di film tersebut.

Sebagai orang tua tentunya harus bijak medampingi dan mengarahkan putra putrinya pada hal yang positif. Melalui tayangan tesebut orang tua dan pendidik bisa mengambil pelajaran penting. Darah serumpun, bahasa, dan latar kehidupan yang hampir 
sama dapat dijadikan sebagai media untuk menamkan karakter anak dan menstimulus dengan arahan yang benar.

Berangkat dari isu di atas, kini peneliti melakukan observasi terhadap anak kandung dan saudara pada tanggal 12 Februari 2018 di lingkungan jl. Dewi Khunti Pulosari RT/RW 05/01 Jambon Ponorogo. Hipotesis yang dapat peneliti ambil pada tahap observasi adalah bahwa film animasi yang banyak ditonton anak usia dini di lingkungan tersebut adalah film animasi "Upin dan Ipin". Film ini diasumsikan mempunyai nilai-nilai pendidikan dan disenangi anak-anak. Dikuatkan dalam halaman Diakses www.putramelayu.web.id/2014/09/sejarah upin dan ipin tanggal 13 Februari 2018. Jika dibandingkan dengan film animasi lain, film animasi Upin-Ipin terkesan istimewa. Film yang berdurasi panjang itu merambah di televisi dengan daya pikat kuat karena bahasa, logat, serta nilai budayanya yang hampir sama dengan kehidupan anak usia dini di Indonesia.

Dengan pendeskripsian masalah di atas, peneliti merasa sangat perlu mengadakan penelitian dengan harapan dapat membawa dampak positif dan perubahan pada paradigma orang tua terkait dampak tayangan yang ditonton dan memberikan pendampingan terhadap mereka. Dalam penelitian ini, peneliti mengambil judul "Inspirasi Kisah filmmografi Upin dan Ipin Dalam Menstimulasi Character Building Anak Usia Dini" Penelitian ini dianggap penting untuk mengetahui dampak film animasi "Upin dan Ipin" terhadap perkembangan stimulus Character Building anak usia dini.

\section{METODE}

Penelitian ini menggunakan pendekatan kualitatif. Pendekatan penelitian yang digunakan adalah studi kasus, yaitu suatu deskripsi intensif dan analisis fenomena penayangan film "Ipin dan Upin" terhadap perkembangan stimulus Character Building anak usia dini di lingkungan jl. Dewi Khunti Pulosari pada lingkungan RT/RW 05/01 Jambon Ponorogo. Kemudian, peneliti mengambil objek penelitian di lingkungan RT/RW 05/01 dikarenakan banyaknya anak usia dini di lingkungan tersebut yang melihat tayangan film animasi. Penjajagan awal di lapangan pada tanggal 12 Februari 2018, peneliti mengambil objek sembilan anak usia dini dan delapan orang tua anak-anak yang ada di lingkungan tersebut. Sumber data primer dalam penelitian ini adalah kata-kata dan tindakan anak-anak yang menjadi objek material penelitian, selebihnya adalah dokumen dan pendukung yang lain.

Teknik pengumpulan data yang digunakan adalah observasi berperan serta (participan observation), wawancara mendalam (in depth interiview) bersama sembilan informan dari pihak orang tua dan sembilan informan dari anak usia dini di lingkungan jalan Dewi Kunthi Pulosari. dan dokumentasi (document review) (Sugiyono, 2005: 309). Pada bagian ini peneliti melakukan pengambilan data sebanyak sepuluh kali. Dokumentasi peneliti 
ambil dari berbagai sumber di antaranya adalah video milik objek penelitian, skenario dari internet serta gambar-gambar yang berasal dari buku.

Teknik analisis data yang digunakan dalam penelitian ini adalah konsep yang diberikan Miles \& Huberman yang mengemukakan bahwa aktivitas dalam analisis data kualitatif dilakukan secara interaktif dan berlangsung secara terus-menerus pada setiap tahapan penelitian sampai tuntas. Data yang telah diverifikasi dan diklasifikasi terkait beberapa anak yang dijadikan objek penelitian akan dianalisis dengan teori yang relevan dengan pembahasan.(Moleong, 2009:171)

\section{HASIL DAN PEMBAHASAN}

\section{Character Building dalam Reorientasi Pendidikan Anak Usia Dini}

Stimulasi adalah setiap kegiatan merangsang kemampuan dasar anak yang dilakukan oleh lingkungan (bapak, ibu, pengasuh anak, anggota keluarga lain) untuk mengoptimalkan tumbuh kembangnya. Kurangnya stimulasi dapat menyebabkan kelambatan tumbuh kembang anak. Melakukan stimulasi yang memadai artinya merangsang otak balita sehingga perkembangan kemampuan gerak, bicara, bahasa, sosialisasi dan kemandirian pada balita berlangsung secara optimal sesuai umur anak (Mahfoed, 2005: 11).

Masa anak usia dini sering disebut dengan istilah "golden age" atau masa emas. Pada msa ini hampir seluruh potensi anak mengalami masa peka untuk tumbuh dan berkembang secara cepat dan hebat. Apabila anak diberi stimulasi secara intensif dari lingkungan, maka anak akan mampu menjalani tugas perkembanganya dengan baik (Ida Suhada, 2016: 10). Anak usia dini memiliki ciri-ciri kepribadian yang unik. Beberapa ahli pendidikan dan psikologi memandang bahwa periode ini adalah periode yang sangat penting yang perlu penanganan sebaik mungkin. Maria Montessori (Elizabeth B.Hurlock, 1978: 13) berpendapat bahwa usia 3-6 tahun merupakan periode sensitif atau masa peka yaitu suatu periode dimana suatu fungsi tertentu perlu dirangsang, diarahkan sehingga tidak terhambat perkembangannya. Sementara itu, Erikson, E. H (Helms \& Turner, 1994: 64) memandang periode ini sebagai fase sense of initiative. Pada periode ini anak harus didorong untuk mengembangkan inisiatifnya seperti kesenangan untuk mengajukan pertanyaan dari apa yang dilihat, didengar dan dirasakan. Jika anak tidak mendapat hambatan dari lingkungannya, maka anak akan mampu mengembangkan inisiatif, daya kreatifnya, dan halhal yang produktif dalam bidang yang disenanginya (Erna wulan syaodah, 2013: 4).

Istilah karakter dihubungkan dan dipertukarkan dengan istilah etika, akhlak, dan/atau nilai serta berkaitan dengan nilai moral dan berkonotasi positif (bukan netral). Karakter adalah sifat-sifat kejiwaan, akhlak, atau budi pekerti yang membedakan seseorang dengan yang lain; tabiat dan watak. Karakter artinya mempunyai tabiat, mempunyai 
kepribadian dan watak. Dengan demikian, karakter adalah nilai-nilai yang unik baik yang terpatri dalam diri maupun terejawantahkan dalam perilaku. Karakter secara koheren memancar dari hasil olah pikir, olah hati, olah rasa dan karsa serta raga seseorang.

\section{Kisah Upin Upin Sebagai Media Pengukur Karakteristik Anak Usia Dini}

Dituturkan Fahmi Kisah adalah sebuah dongeng, cerita, dan hikayat. proses kisah itu disampaikan dinamakan pengisahan. Proses penyampaian secara makna tertulis bahwa wacana yang bersifat cerita baik berdasarkan pengamatan maupun berdasarkan rekaan dan narasi (Fahmi, 2006: 379). Sejarah pembuatan film Upin-Ipin pada awalnya dibuat oleh M. Nizam Razak, M.Sofwan Abdul Karim dan Usamah Zaid, pemilim Let'Copaqu Ketiganya merupakan bekas mahasiswa dari Multimedi University Malaysia yang awalnya bekerja sebagai pekerja di sebuah organisasi animasi sebelum akhirnya bertemu dengan bekas pedagang minyakdan gas, Haji Burhanuddin Radzi dan istrinya bernama H. Ainon Ariff pada tahun 2005 lalu membuka organisasi Les' Copaque.

Les' Copaque sendiri terdengar seperti istilah dalam bahasa Perancis, padahal nama hanya plesetan dari campuran Melayu dan Inggris, sehingga dibaca 'LES KOPEK'. Kopek dalam bahasa melayu berarti 'KUPAS' (misalnya: kopek buah, berarti 'mengupas buah'). Jadi, Les Kopek berarti kupasan terakhir yang siap santap. Pada awalnya Upin-Ipinditayangkan khusus untuk menyambut Ramadhan pada tahun 2007 untuk mendidik anak-anak mengenai arti dan kepentingan bulan suci. (Putra melayu:2018)

Sambutan meriah terhadap kartun pendek ini mendorong Let' Compaque agar menerbitkan satu musim lagi menyambut bulan Ramadhan yang seterusnya. Nizam percaya aspek kebudayaan Malaysia yang berlatarkan sebagai sebuah kampung sederhana pasti dapat menarik minat pasar Internasional seperti pada kartun animasi Doraemon asal Jepang dapat laris diselur dunia meskipun berlatar belakang budaya setempat dan bukannya budaya internasional. Nasution menyatakan bahwa menonton tidak dapat dilihat sebagai aktivitas satu dimensi. Aktifitas ini dapat dilihat dari beberapa dimensi salah satunya adalah tipe penonton, dimana orang menonton televisi dengan tipe yang berbeda-beda, ada yang menonton dengan penuh perhatian ada juga tipe penonton yang sambil berperilaku. Lantas, bagaimana menarasikan aktivitas menonton dengan kegiatan komunikasi verbal anak usia dini? Itulah pernyataan yang hendak diselesaikan pada bahasan selanjutnya. ( Nasution ,2000: 20)

\section{Upin dan Ipin; Filmografi Animasi dan Komunikasi dalam Mendekonstruksi Pesan Character Building}

Anak yang mendapatkan stimulasi akan lebih memiliki kemampuan yang optimal dan lebih siaga menerima tugas perkembangan di tingkat yang lebih tinggi. Waktu yang terbaik untuk memberikan stimulasi dapat dimanapun dan kapanpun. Nilai stimulus bagi anak usia dini 61 
pada films animasi Upin-Ipin tergambar jelas dari catatan interview dengan ibu Siti Yulianingsih:

Ada logat dan bahasa khas pemeran Meimei. Banyak sekali mbak, khasnya geh betul betul betul. Kadose sedanten mbak,bingung seng pundi lha kuatah. Enten, carane matur utawi logate Upin-Ipin betul betul betul.

Data interview di atas diperkuat dengan data dokumentasi yang dikumpulkan peneliti pada tanggal 12 Mei 2018, gambar seting film upin dan ipin. Keceriaan dan kekhasan dari beberapa karakter menjadikan stimulus bagi anak untuk mengucap suatu kata. Meimei yang comel, Upin yang ceria, dan Jarjit yang pandai berpantun. Stimulasi bagi pendidikan anak usia dini menurut hemat peneliti sangat penting. Lingkungan sebagai media interaksi akan memberi kontribusi terhadap perkembangan karakter anak usia dini. Senada dengan teori behavioristik bahwa stimulus itu akan mempengaruhi hasil belajar. Film animasi upin ipin ini akan memberikan pembelajaran baik karena di dalamya mengandung resistensi stimulus guna mengembangkan karakter anak lebih baik.

Syarat pendidikan karakter pada film Upin-Ipin kental pada penokohan masingmasing karakter. Ketika anak sering melakukan aktivitas menonton film animasi tersebut, secara perlahan karakter dari penokohan masing-masing akan memberi dampak kepada karakter anak di lingkungan Jl. Dewi Kunthi Pulosari. Hal tersebut diperkuat dengan data interview dan testimoni bersama ibu Adi Nova selaku orang tua Kinara setelah beberapa hari anaknya melihat film kartun animasi Upin-Ipin:

Menirukan mengaji, yang paling terlihat geh menyanyi mbak,. kemajuane katah mbak, nerokne ngaji, nyanyi rumaos kulo katah mbak. Enten, menyanyi, mengaji, malah mainan peran ngoteniko lho... .kados wayang.

Perubahane lare nggih wonten mbak, contone pas Upin-Ipinmengaji larene geh nderek ngaji. Derek ngapalen, ugi pas nyanyi larene nggih nderek nyanyi.

Lintune niku, anak-anak nggih berusaha ngafalaken surat pendek, menyannyi dan menghafal huruf hijaiyah

Karakter anak usia dini tidak menonjol seperti halnya usia dewasa, namun dengan meniru dan memberi respon yang bagus seperti halnya di atas minimal dapat membuat orang tua tidak khawatir. Pendidikan karakter ditegaskan oleh ketiga data yang menyiratkan makna bahwa film animasi Upin-Ipin telah memberikan pesan pendidikan karakter kepada anak usia dini. Namun demikian, pola perilaku, kebiasaan, dan kepribadian anak secara persentase $80 \%$ tetap terletak pada pola asuh dan didikan orang tua. Artinya, bagaimana tumbuh kembang pola pikir dan sikap anak-anak akan ditentukan sepenuhnya oleh informasi dan penegetahuan yang tersimpan di otak ereka.

Ibu adalah sumber utama pendidikan bagi anak-anak dalam lingkungan keluarga. Pendidikan oleh ibu selayaknya dilakukan dengan kelembutan, kasih sayang, ketulusan, dan pengorbanan yang luar biasa. Pengaruh ibu dalam pembentukan kepribadian anak cenderung 
lebih dominan dibanding dengan pola pendidikan yang dituangkan ayah kepada anaknya. Meskipun demikian, peran ayah juga tetap dibutuhkan guna memberi kontribusi pada aspekaspek pengembangan karakter, kedisiplinan, ketangguhan, kemandirian, tanggungjawab, dan perkembangan gender. Ada ada masanya anak perempuan harus dekat dengan ibunya dan anak laki-laki dekat dengan ayahnya. Begitu juga sebaliknya, akan ada masanya dimana anak perempuan memerlukan sosok ayah dan anak laki-laki memerlukan sosok ibu. Refleksi demikian dikuatkan dengan hasil interview kepada Ibu Rumaswatik selaku ibunda Miza terkait pendidikan karakter. Berikut data yang peneliti sajikan:

Anak-anak selalu kami dampingi mbak, kalau tidak bapaknya geh saya sendiri yang mendampingi, uhtinya, terkadang nggih kakakny

Dukungan kelurga, pendampingan, dan arahan orang tua dalam memilih film animasi akan menjadi penentu keberhasilan pendidikan karakter anak usia dini. Subtansi fungsi keluarga hakikatnya adalah melindungi para anggota keluarga terlebih kepada anak-anak dari hal-hal yang membahayakan baik di dunia maupun di akhirat kelak.

Sejalan denga Piaget ang menyatakan bahwa saat anak-anak berkembang, mereka mengalami kemajuan dalam pemahaman masalah-masalah sosial. Mereka meyakini bahwa pemahaman sosial ini muncul melalui interaksi atau saling menerima dan memberi kepada teman sebaya. Dalam tatanan kelompok teman sebaya, anak-anak memiliki kekuatan dan status yang sama. Mereka secara leluasa dapat saling memberi masukan dan bernegosiasi untuk memecahkan berbagai persoalan yang muncul. Pengalaman akan menjadi bekal belajar yang kondusif untuk pengembangan moral anak.( Ani Christiani, 2002:292)

Pada masa bayi atau masa vital, perkembangan skema pola raih dan pola isap sangat dominan dan cepat. Semua itu untuk kebutuhan fundamental yang juga disebut dengan masa fundamental. Pertumbuhan jasmaniah di masa itu turut berlangsung cepat. Setelah beranjak usia tiga tahun, sifat pribadi anak yang akan menonjol adalah seperti raja. Mereka ingin dilayani secara tendensius, ingin menjadi yang superior, selalu berkeinginan untuk diperhatikan, dan tidak boleha ada saingan dalam kehidupan mereka. Sifat egosentris di masa itu masih melekat dalam jati diri anak-anak. Ida Suhada,2016:45)Data observasi di halaman rumah bapak haji Koderi pada bulan Mei tahun 2018 memberikan gambaran sebagai berikut:

"iqul menjawab" aku seneng dadi ipin ipin mbak" nek aku seneng dadi Meimei" peneliti dan ibunya kinara memberikan penghargaan dengan tersenyum dan memberi tepukan kepada keduanya.

Data-data di atas menegaskan bahwa film aniamsi Upin-Ipin layak sebagai tontonan pilihan anak usia dini tanpa melupakan hakikat peran orang tua dalam proses pendidikan anak, yakni mendampingi dan mengarahkan ke dalam hal-hal yang positif.

Orang tua adalah pendidik pertama bagi anak-anaknya. Memilih film atau tontonan anak adalah salah satu kewajiaban orang tua. Orang tua juga harus ikut serta dalam 
mendampingi dan mengarahkan anak-anak mereka agar tontonan itu memberi nilai pesan karakter yang baik guna perkembangan karakter anak usia dini. Proses stimulasi perkembangan anak merupakan salah satu tugas orang tua, sesuai halnya data hasil observasi di kediaman bapak Jumadi pada tanggal 21 Juni 2018 yang peneliti paparkan sebagai berikut:

Dalam tanyangan Upin dan Ipin, kak Ros memeragakan pembuatan es krim buah. "kemudian dia bertanya mboten syah tumbas geh buk es krim, kak Ros pinter ". Upin-Ipin disuruh kak Ros mengantar barang. Dalam perjalanan es krim terjatuh, dilahapnya es krim yang tersisa dengan niat agar tidak diminta kembarannya itu. Dengan respon yang cepat iqul berkata " kok gak diparingi geh buk?

Inilah salah satu tayangan yang dipilih anak yang memberikan kemajuan positif. Seorang komunikator dapat menggunakan media kedua untuk melancarkan proses komunikasi apabila komunikan berada di tempat yang relatif jauh dan memiliki kuantitas dengan jumlah yang relatif banyak. Surat, telepon, teleks, surat kabar, majalah, radio, TV, film, merupakan sebagian contoh media kedua yang sering digunakan dalam komunikasi. Pemilihan film animasi anak-anak di lingkungan jalan Dewi Khunti terutama film Upin-Ipin dapat menstimulasi kamunikasi verbal anak untuk lebih baik. Namun, di era modern seperti saat ini, selain komunikas verbal anak usia dini juga harus dikenalkan komunikasi virtual. Komunkasi virtual sangat memiliki peran penting di era ini dan yang akan datang sembari berkembangnya peradaban.

Anak-anak usia dini di usia yang cukup matang memiliki kerentanan dalam pertumbuhan dan perkembangan kecerdasan emosional dan karakter. Sebagai orang tua yang memiliki otoritas tanggung jawab kepada anak-anak harus pandai-pandai untuk mengatur dan mengontrol pola asuh anak agar menjadi anak yang memiliki keseimbangan kecerdasan. Kecerdasan linguistik misalnya, anak mampu berkomunikasi dengan teman sebaya secara baik. Tidak berhenti pada hal itu, kecerdasan linguistik secara bertahap akan memengaruhi pola karakter anak-anak. Dari berbagai sumber data yang dikumpulkan, peneliti mengarah pada hal positif tentang karakter film Upin-Ipin. Hal ini tersurat jelas pada pemaparan observan Bapak Jumadi selaku ayahanda Iqul pada bulan Mei tahun 2018 sebagai berikut:

"Bapak... .bapak... .Upin-Ipin adik pundi ?" tumbasno balon Upin-Ipin bapak! Bapaknya menjawab, hayooo pripun nek matur? Upin-Ipin nopo banter-banter ngoten? Langsung merespon dik iqul menjawab... ."geh minta maaf bapak". Dengan nada rendah iqul mengulangi perkataanya." Lhaaa ngoten nek matur, adik pinter..

Sesuai dengan karakteristik film pendidikan, film Upin-Ipin tampaknya telah memenuhi syarat dan layak ditonton oleh anak usia dini. Karakter yang khas, bahasa, dan 

Vol. 01, No. 01, Januari-Juni 2019 setting tempat yang natural membuat film animasi ini cocok menjadi pilihan orang tua sebagai sarana edukasi anak-anak usia dini. 


\section{KESIMPULAN}

Terdapat nilai-nilai pendidikan karakter dalam film kartun Upin-Ipin diantaranya adalah bertakwa, bertanggung jawab, disiplin, gemar membaca, jujur, sopan, peduli, sikap yang baik, toleransi, kreatif, mandiri, rasa ingin tahu, semangat kebangsaan, menghargai, dan bersahabat. Berdasarkan penelitian yang sudah dilakukan, peneliti menarik kesimpulan bahwa antusiasme anak usia dini di jalan Dewi Khunti (RT 05/RW 01) sangat besar. Berdasarkan hasil penelitian, telah diketahui bahwa karakter tokoh pada film animasi UpinIpin telah memberikan stimulus dalam penanaman karakter anak usia dini yang sesuai dengan perkembangan anak usia dini. Selain itu, film anamisasi tersebut dapat memberikan contoh yang efektif dalam membina karakter anak usia dini.

\section{AKNOWLEDGEMENT}

Pada kesempatan ini, peneliti banyak memberi apresiasi moril dan akademis kepada Lembaga Penelitian dan Pengabdian Masyarakat (LP2M) INSURI Ponorogo yang telah mengorganisir dan memfasilitasi kegiatan penelitian dosen tetap INSURI Ponoogo secara berkala. Penelitian yang dilaksanakan oleh dosen INSURI Ponorogo merupakan salah satu bentuk aktualisasi Tri Darma Perguruan Tinggi yang harus dilaksanakan secara konsisten tiap tahun. Dengan adanya dana hibah penelitian dari LP2M INSURI Ponorogo di tahun 2018, kini peneliti merasa lebih ringan dalam melakukan proses penelitian mulai dari perencanaan hingga simulasi penelitian.

\section{REFERENSI}

Ardy, Nova Wiyani. 2014. Mengelola dan Mengembangkan Kecerdasan Sosial dan Emosional Anak Usia Dini. Ar-Ruzz Media: Yogyakarta.

Cristina, Ani. 2002. Parenting Guide(panduan pendampingan anak usia pra sekolah). Filla Press: Sidoarjo.

Elvinaro Ardianto dan Lukiati komala E. 2005. Komunikasi Masa. PT. Remaja Rosdakarya: Bandung.

Erna Wulan Syaodih. 2013. Perkembangan Sosial Emosional Anak TK. Jurnal Perkembangan Sosial Emosional Anak TK, Vol.1 No.1.

Moleong Lexy. 2000. Metodologi Penelitian Kualitatif . Bandung: PT Remaja Rosda Karya Mursid. 2016. Pengembangan Pembelajaran PAUD. Remaja Rosdakarya. Bandung 2015. Pengembangan Pembelajran PAUD. PT: Remaja Rosda Karya: Bandung

Nasution. 2000. Pengaruh menonton tayangan kekerasan terhadap perilaku agresif anak. UI: Fakultas Psikologi, Depok.

Nurani, Yuliani. 2004. Belajar dan Pembelajar. UNJ Press: Jakarta.

Suhada, Ida. 2016. Psikologi Perkembangan Anak Usia Dini. PT: Rosda Karya, Bandung

Tri sukitman, Tri. 2015. Bimbingan Konseling Berbasis Pendidikan Karakter. Diva Press: Yogyakarta

Uchjana, Onong Effendy. 2007. Ilmu Komunikasi. PT. Remaja Rosdakarya, Bandung http://www.putramelayu.web.id/2014/09/sejarah upin dan ipin diakses pada tanggal 13 Februari 2018 